\title{
Study on Stopping Ability of a Ship Equipped with Azimuth Propeller
}

\author{
Jong-Yong Park ${ }^{1}$, Pilgun Oh $\circledast^{2}$, Taejin Kim $\circledast^{3}$ and Jun-Ho Lee ${ }^{4}$ \\ ${ }^{1}$ Assistant Professor, Department of Naval Architecture and Marine System Engineering, Pukyong National University, Busan, Korea \\ ${ }^{2}$ Assistant Professor, Department of Graphic Art Information Engineering, Pukyong National University, Busan, Korea \\ ${ }^{3}$ Assistant Professor, Department of Oceanography, Pukyong National University, Busan, Korea \\ ${ }^{4}$ Assistant Professor, Training Ship NARA, Pukyong National University, Busan, Korea
}

KEY WORDS: Stopping ability, Azimuth propeller, Research vessel NARA, Full scale maneuvering trial, Track reach

ABSTRACT: An azimuth propeller can generate thrust in all directions by rotating its housing with an electric motor. An azimuth propeller can be operated using several methods to stop a ship. This study aims to derive an efficient method to stop a ship safely using an azimuth propeller through full-scale maneuvering trials with the research vessel "NARA" of Pukyong National University in $4.63 \mathrm{~m} / \mathrm{s}$ (9 kts). Five methods with different azimuth propeller operations were tested to stop the ship. The test results confirmed that the simultaneous use of the thrust and the hydrodynamic force acting on the strut is the most effective method to stop the ship.

\section{Introduction}

An azimuth propeller refers to a propeller capable of generating thrust in all directions by rotating its housing through an electric motor. It is used for offshore specialized vessels because it improves berthing and maneuvering performances in the port, and it enables dynamic positioning. A maritime autonomous surface ship, which has recently attracted attention, is likely to be equipped with a bow thruster and an azimuth propeller, rather than a general propulsion and steering gear system, to implement automatic berthing and un-berthing. Therefore, continuous studies will be necessary for the maneuvering performance of ships equipped with an azimuth propeller.

The maneuvering performance of ships are primarily categorized into turning, course changing, and stopping abilities. As a ship is typically equipped with two or more azimuth propellers, various methods can be used to manipulate the propellers for turning and course changing, as well as for stopping a ship. According to ship captains and maritime pilots, ships equipped with azimuth propellers can reduce the track reach by $50 \%$ or more at the time of emergency stop compared with ships equipped with general single-shaft propellers, depending on the stopping method (Nowicki, 2014). Previous studies on the stopping ability of ships have focused primarily on methods using maneuvering mathematical models
(Nakato et al., 1976; Yoshimura, 1994). Recent studies have investigated methods for estimating the stopping ability of full-scale ships using the free-running model test or computational fluid dynamics (Ueno et al., 2017; Sun et al., 2018). However, few studies have reviewed methods for improving the stopping ability of ships through full-scale maneuvering trials using azimuth propellers.

This study aims to derive an effective method to safely stop a ship through a full-scale maneuvering trial using azimuth propellers. The full-scale maneuvering was performed using the research vessel "NARA" of Pukyong National University. Five different approaches were tested to stop ships by varying the operation of azimuth propellers. Using the test results, the track reach of the ship was analyzed to determine the most effective method.

\section{Preparation of Full-Scale Maneuvering Trial}

\subsection{Test vessel and azimuth propeller}

This study was conducted using the research vessel NARA of Pukyong National University. The general arrangement and specifications of NARA are shown in Fig. 1 and Table 1, respectively.

NARA was equipped with two Rolls-Royce US 155 contra- rotating propellers (CRPs), which were azimuth propellers equipped with a pair of CRPs. The appearance and specifications of the azimuth propeller of NARA are shown in Fig. 2 and Table 2, respectively.

Received 23 November 2019, revised 30 January 2020, accepted 6 February 2020

Corresponding author Jun-Ho Lee: +82-51-629-5995, leejh@pknu.ac.kr

(c) 2020, The Korean Society of Ocean Engineers

This is an open access article distributed under the terms of the creative commons attribution non-commercial license (http://creativecommons.org/licenses/by-nc/4.0) which permits unrestricted non-commercial use, distribution, and reproduction in any medium, provided the original work is properly cited. 


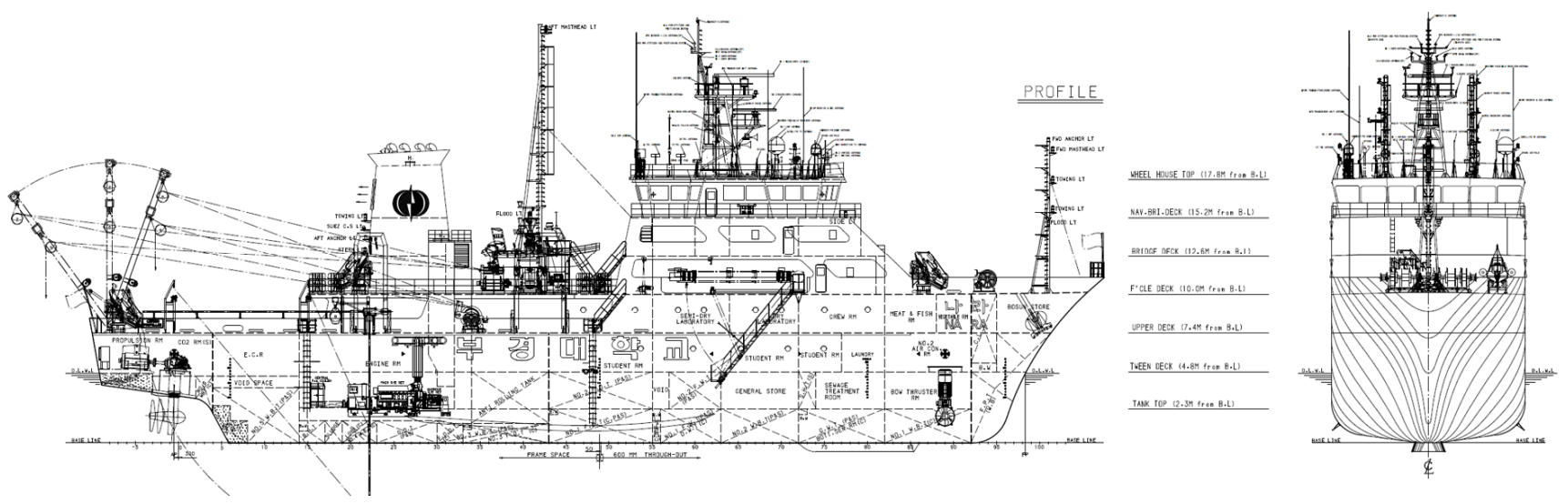

Fig. 1 General arrangement of NARA

Table 1 Principal dimensions of NARA

\begin{tabular}{cc}
\hline Item & Value \\
\hline Length overall, LOA & $70.7 \mathrm{~m}$ \\
Length between perpendicular, LBP & $59.7 \mathrm{~m}$ \\
Breadth & $13.5 \mathrm{~m}$ \\
Draft & $4.7 \mathrm{~m}$ \\
Displacement & $1,494 \mathrm{t}$ \\
Metacentric height, GM & $0.6 \mathrm{~m}$ \\
Designed speed & $7.1 \mathrm{~m} / \mathrm{s}(13.8 \mathrm{kt})$ \\
\hline
\end{tabular}
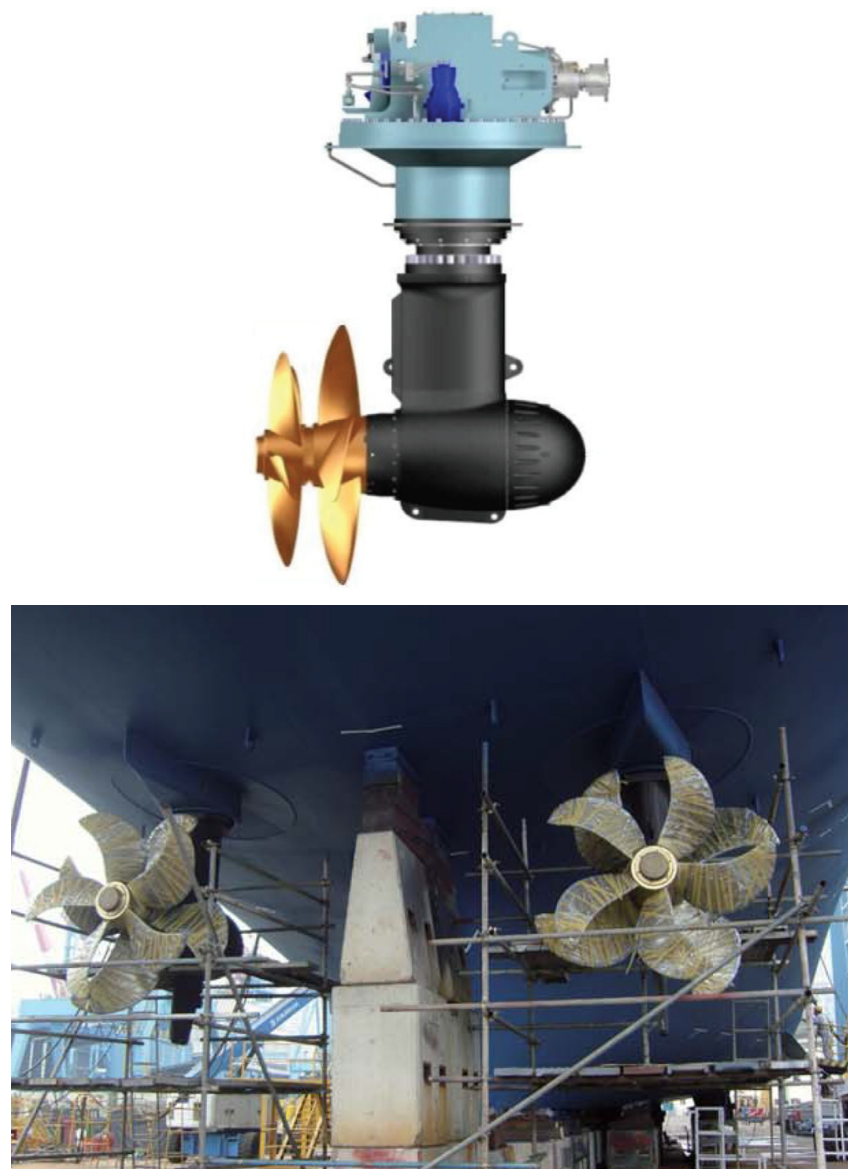

Fig. 2 Azimuth propeller of NARA
Table 2 Azimuth thruster units of NARA

\begin{tabular}{cc}
\hline Item & Value \\
\hline $\begin{array}{c}\text { Max. power on the input shaft } \\
\text { Main engine nominal speed }\end{array}$ & $1,100 \mathrm{~kW}$ \\
Max. allowable torque on the & $0-1200 \mathrm{rpm}$ \\
input shaft & $8.75 \mathrm{kN} \cdot \mathrm{m}$ \\
Gear reduction ratio in unit & $5.311: 1$ \\
Propeller type & $\begin{array}{c}\text { Contra-Rotating propellers (CRP), } \\
\text { Monoblock, Fixed pitch } \\
2200 \mathrm{~mm} / 1950 \\
\text { Propeller diameter }\end{array}$ \\
(front / aft propeller) \\
Number of propeller blades & $4 / 5$ (front / aft propeller) \\
Propeller revolution speed & $0-226 \mathrm{rpm}$ \\
Stem length & $3,620 \mathrm{~mm}$ \\
Steering speed & $3 \mathrm{rpm}$ \\
\hline
\end{tabular}

\subsection{Test methods}

The International Maritime Organization enacted and legislated steering performance standards (maneuverability resolution) in 1994, providing the minimum maneuvering performance required for ships. Crash astern and stopping inertia tests were performed to identify the stopping ability, and the crash astern test was conducted for test-driving commercial vessels. The crash astern test method is as follows. The propeller is windmilled by discontinuing fuel supply to the engine of the ship moving forward at a certain speed, and the engine rotation is reversed to stop the ship when the engine reaches approximately $20 \%$ of the rotational speed at the maximum continuous rate. The data to be derived from the crash astern test are defined in Fig. 3, including the track reach, head reach, and lateral deviation during the stop (ITTC, 2017).

The stopping process of a ship, as previously described, is a general method applicable to all types of vessels. For ships equipped with azimuth propellers, additional ship stopping methods exist. The first method is to stop a ship by rotating an azimuth propeller by $180^{\circ}$ to change the thrust direction when the angle of the azimuth propeller in the moving-forward situation is defined as $0^{\circ}$. Although this method 
Table 3 Case description of the stopping procedure (Nowicki, 2014)

\begin{tabular}{cl}
\hline Case & \multicolumn{1}{c}{ Description } \\
\hline 1 & Inertia stopping (propellers windmilling) with the azimuth angle of deflection $90^{\circ}$ outward \\
2 & Stopping with the azimuth angle of deflection $90^{\circ}$ outwards. Propellers revolutions not changed. \\
3 & $\begin{array}{l}\text { Stopping by turning azimuth around }\left(180^{\circ}\right) \text {. When turning the azimuth, the number of propeller revolutions decreased, and the } \\
\text { propeller revolutions returned. }\end{array}$ \\
4 & $\begin{array}{l}\text { Stopping by changing the propeller direction of revolution. The astern number of propeller revolutions is the same as that } \\
\text { ahead. }\end{array}$ \\
5 & $\begin{array}{l}\text { Stopping by indirect maneuver: deflection of azimuths by } 30^{\circ} \text { outward, with simultaneous reversing of propellers. The astern } \\
\text { number of propeller revolutions is the same as that ahead. }\end{array}$ \\
\hline
\end{tabular}

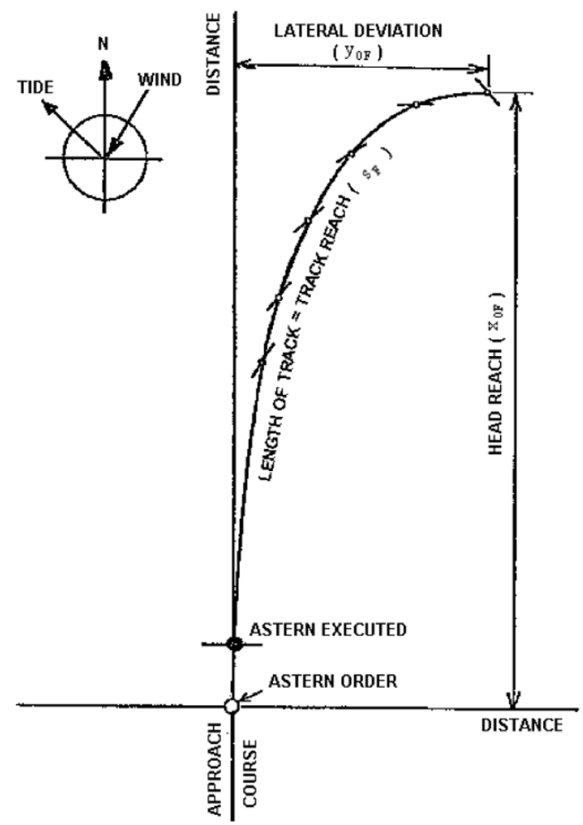

Fig. 3 Definitions used in stopping trials (ITTC, 2017)

improves the stopping ability in comparison with the case of using reverse propulsion, an excessive load can be applied to the propeller blades when rotating the azimuth propeller. The second method is to simultaneously apply the reverse propulsion and rotate the azimuth propeller at a certain angle to additionally use the hydrodynamic force acting on the housing and strut to stop a ship. The rotation of the azimuth propeller at a certain angle results in the generation of lift and drag owing to the angle of attack on the propeller housing and the strut having a shape similar to the blade surface, which can be used to stop the ship. In this study, the five methods used by Nowicki (2014) were tested to stop the ship. Table 3 describes the applied stopping procedures.

\section{Results of Full-Scale Maneuvering Trial}

The full-scale maneuvering trial was conducted on April 23, 2019, near Mijo-myeon in the Southern coast (near latitude: $34.72^{\circ}$, longitude: $128.11^{\circ}$ ). During the trial, the average wind speed and wind direction in this region were $6.5 \mathrm{~m} / \mathrm{s}$, and $15.8^{\circ}$, respectively, and no current was measured. The initial speed was set at $4.63 \mathrm{~m} / \mathrm{s}(9 \mathrm{kts})$, which was approximately $65 \%$ of NARA's service speed. According to the provisions of the International Maritime Organization (IMO, 2002), a stopping test must be conducted at a speed equivalent to $90 \%$ of the service speed; however, our test was conducted at $4.63 \mathrm{~m} / \mathrm{s}(9$ kts) owing to severe hull vibrations at that speed. The measurement period of the test data was $1 \mathrm{~Hz}$. The position information of this vessel were measured by latitude and longitude coordinates, but they were converted into the Universal Transverse Mercator coordinates in this study. The measured velocity was the ground speed, but environmental disturbances such as wind and current in this region prevented the vessel from stopping accurately based on the ground speed. Hence, the track reach, lateral deviation, and time to dead were derived assuming that the vessel stopped when the vessel speed reached $0.46 \mathrm{~m} / \mathrm{s}(0.9$ kts) or less, which was $10 \%$ of the initial speed. Figs. 4 to 8 show the graphs of the test results by each stopping method. The left-side graph shows the vessel speed and track reach, and the right-side graph indicates the trajectory of the ship.

Table 4 shows a summary of the track reach, lateral deviation, and time to dead for each stopping method.

In Cases 1 and 2, which stop the ship by rotating the azimuth propeller $90^{\circ}$ outward, the hydrodynamic force acting on the strut and the housing were used to stop the ship. In Case 3, which stops the ship by rotating the azimuth propeller $180^{\circ}$, and in Case 4 , which stops the ship by reverse propulsion, the thrust of the propeller was used directly to stop the ship. In Case 5, which stops the ship by rotating the azimuth propeller $30^{\circ}$ outward while reversing the propellers, both the hydrodynamic force acting on the strut and the housing as well as the thrust of the propeller were used to stop the ship. The difference between Cases 1 and 2 is the propeller rotation. The acceleration of the fluid due to propeller rotation was added to the movement speed of the hull, thereby forming an angle of attack in the propeller housing and the strut. The difference in the angle of attack of the propeller housing and the strut between Cases 1 and 2 changed the hydrodynamic force in the ship's stopping direction, resulting in a difference in the track reach. The comparison of the results from Cases 3 and 4 reveals that the method of stopping the ship using reverse propulsion reduces the track reach by $21 \%$ compared to that of rotating the azimuth propeller by $180^{\circ}$. This difference is considered to be caused by the difference in the time required for the thrust of the propeller to act in the stopping direction of the ship. As the steering speed of the azimuth propeller 

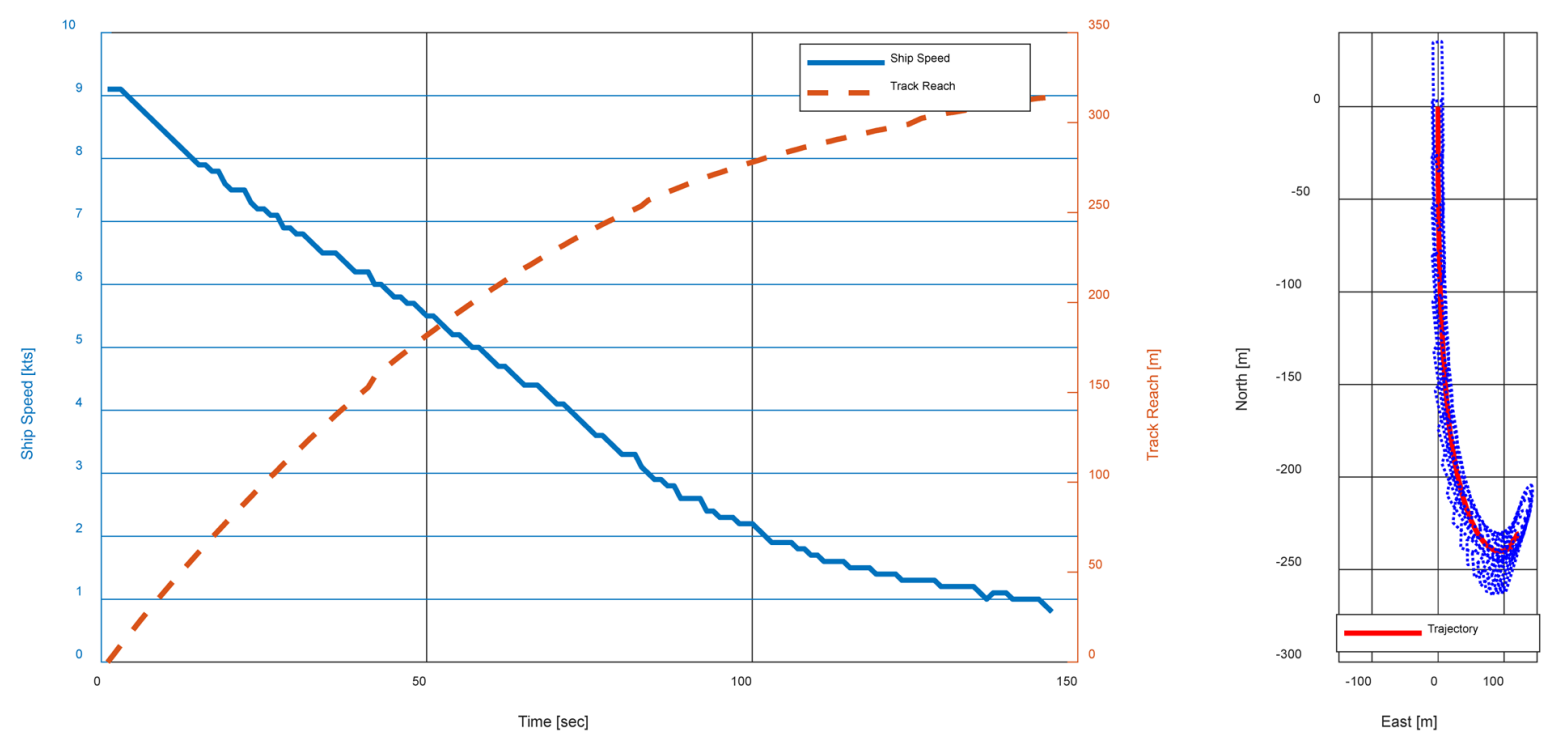

Fig. 4 Stopping test results for 1st stopping mode
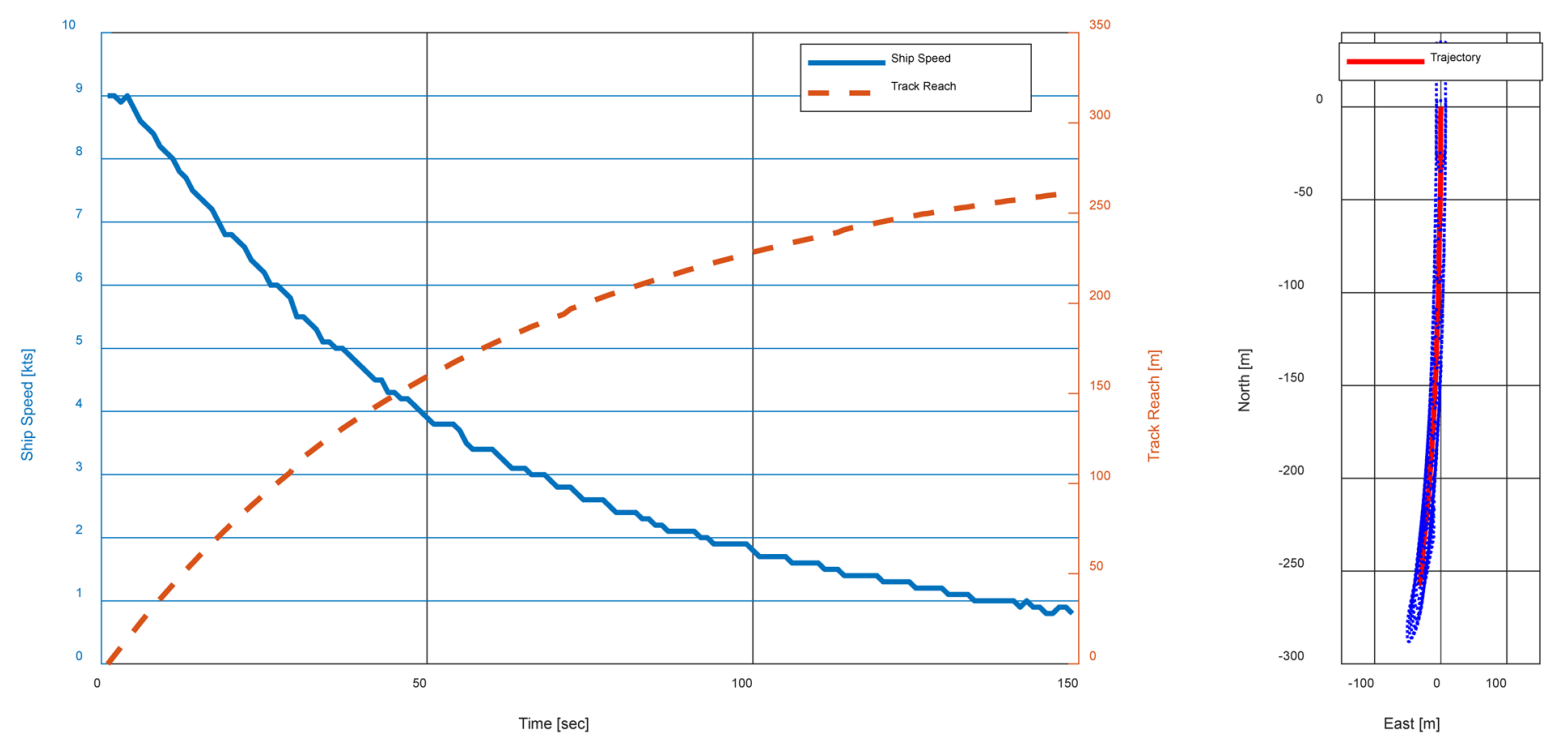

Fig. 5 Stopping test results for 2nd stopping mode
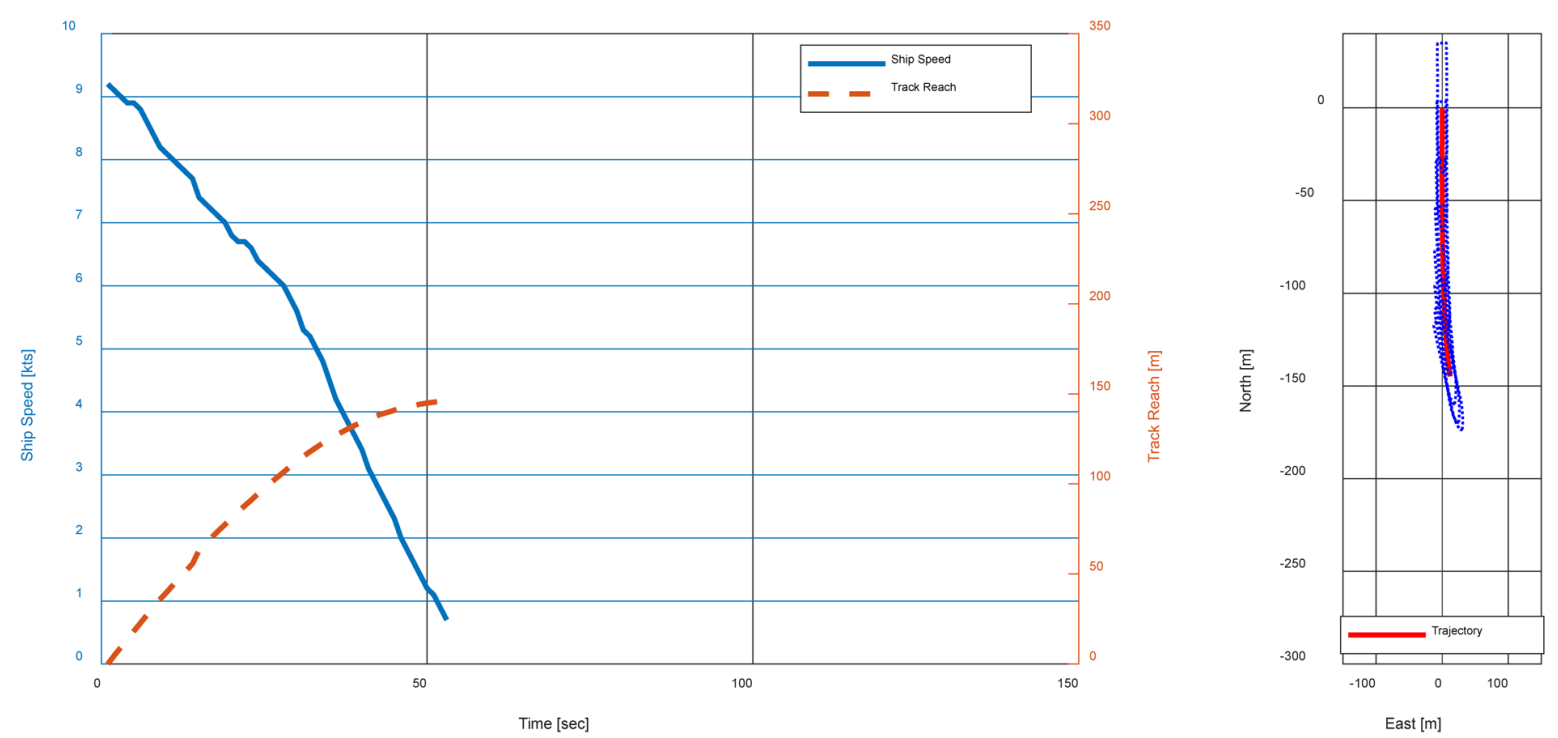

Fig. 6 Stopping test results for 3rd stopping mode 

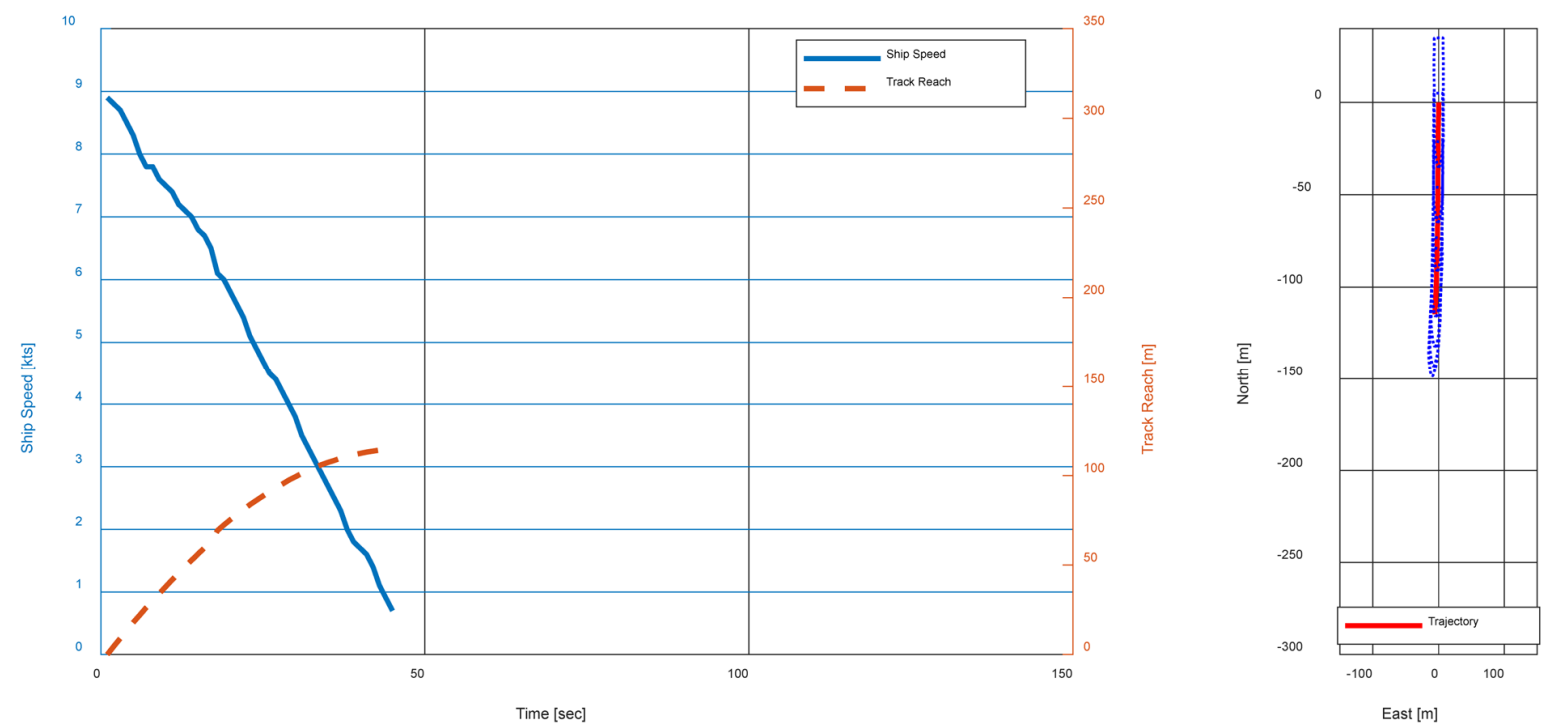

Fig. 7 Stopping test results for 4th stopping mode
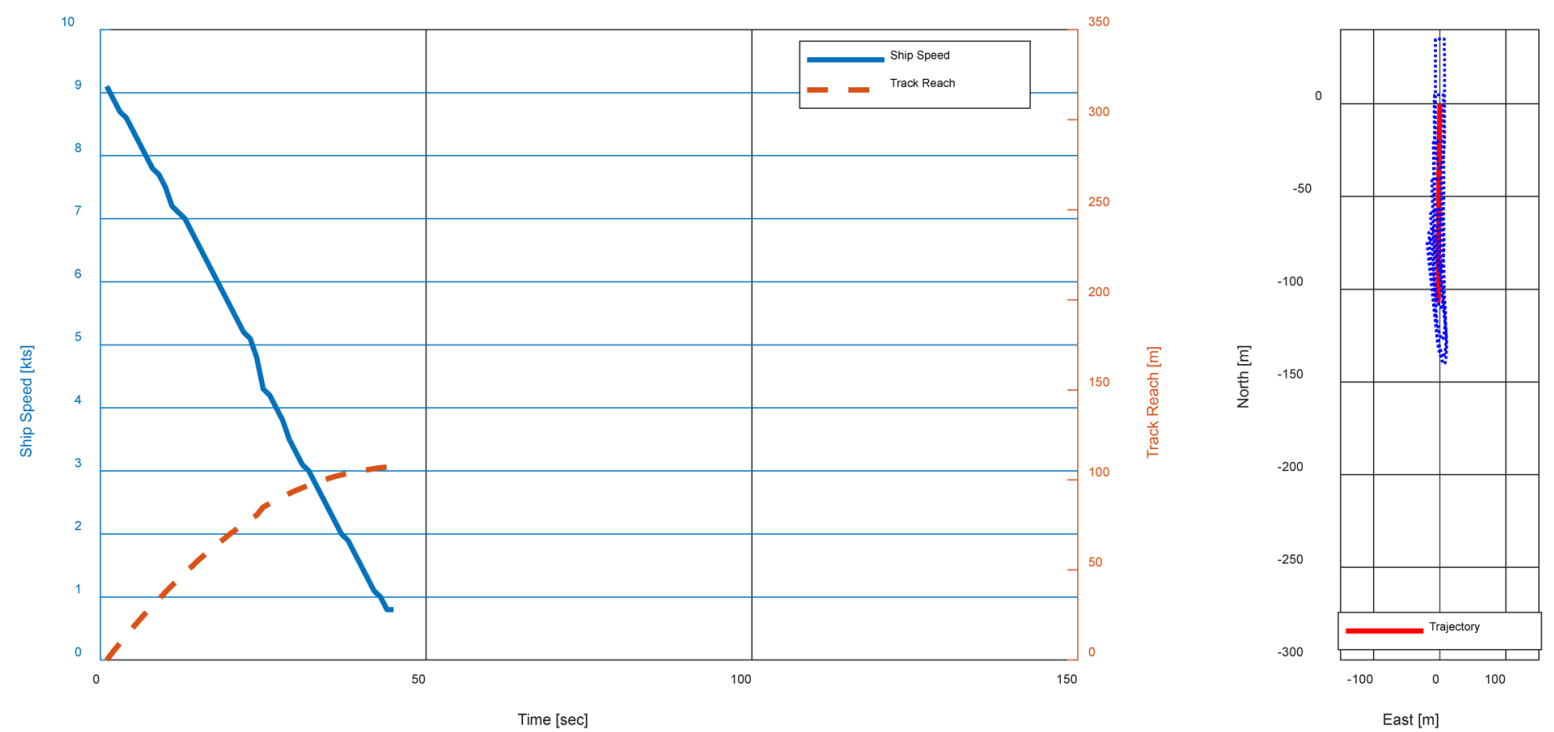

Fig. 8 Stopping test results for 5th stopping mode

Table 4 Stopping test results

\begin{tabular}{ccccccccc}
\hline \multirow{2}{*}{ Case } & \multicolumn{2}{c}{ Track reach, $T R$} & \multicolumn{2}{c}{ Head reach, $H R$} & \multicolumn{2}{c}{ Lateral deviation, $L D$} & \multicolumn{2}{c}{ Time to dead, TD } \\
& $(\mathrm{m})$ & $(\mathrm{LBP})$ & $(\mathrm{m})$ & $(\mathrm{LBP})$ & $(\mathrm{m})$ & $(\mathrm{LBP})$ & 2.04 & 155 \\
\hline 1 & 313.84 & 5.26 & 230.83 & 3.87 & 121.58 & 32.65 & 0.55 & 157 \\
2 & 260.88 & 4.37 & 257.75 & 4.32 & 2.43 & 11.85 & 0.20 & 61 \\
3 & 145.80 & 2.44 & 144.83 & 1.85 & 56 \\
4 & 114.70 & 1.92 & 114.74 & 1.92 & 5.59 & 0.09 & 56 \\
5 & 107.15 & 1.79 & 106.99 & 1.79 & 3.54 & 0.06 & 56 \\
\hline
\end{tabular}

was $3 \mathrm{rpm}$ according to the specifications listed in Table 2, approximately $10 \mathrm{~s}$ was required to rotate the azimuth propeller by $180^{\circ}$. In Case 3 , reverse propulsion began after the rotation of the azimuth propeller was completed. Fig. 6 shows that the speed reduction rate increased after approximately $25 \mathrm{~s}$. Meanwhile, because the reverse propulsion in Case 4 began immediately after a deceleration in rotation when the stopping test was initiated, the thrust generation time could be shortened in the stopping direction of the ship, in comparison to Case 3. Furthermore, in both methods, the slipstream of the propeller was directed to the stern, which affected the pressure distribution on the stern and hence the resistance acting on the hull. The propeller in Case 3 was located closer to the hull than compared with Case 4 , which could affect the increase in distance traveled by the ship before stopping. The results of Case 5 show that this method is the most effective for 
stopping the ship among all the methods. Rotating the azimuth propeller by $30^{\circ}$ reduces the thrust in the stopping direction by approximately $13 \%$, but the thrust of the propeller housing and strut due to the angle of attack acts additionally in the direction opposite to the traveling direction of the ship. The overall results confirmed that the methods of Cases 3, 4, and 5, which directly used the thrust of the propeller to stop, was more effective in stopping ships compared to the methods of Cases 1 and 2, which used the hydrodynamic force acting on the propeller housing and the strut to stop the ship.

\section{Conclusion}

To determine the efficient operation method of azimuth propellers to stop a ship, a full-scale maneuvering trial was conducted using the research vessel NARA of Pukyong National University. First, the method of directly using the thrust of azimuth propellers to stop the ship was more effective than the stopping method using the hydrodynamic force of the propeller housing and strut. Next, the method of stopping the ship using reverse propulsion was more effective than rotating the azimuth propeller by $180^{\circ}$. Subsequently, the method of simultaneously using the thrust of the azimuth propeller, the hydrodynamic force of the propeller housing, and the strut was the most effective in stopping the ship.

The limitations of this study are as follows. First, the conclusions of this study might not be applicable to all ship speeds. The change in ship speed varied the change in the angle of attack between the propeller housing and the strut, which could yield different test results. Next, the operation angle of $30^{\circ}$ for the azimuth propeller, which was applied in Case 5, could not be guaranteed to be optimal for stopping the ship. The method in Case 5 might yield different results depending on the operation angle of the azimuth propeller because it simultaneously used the thrust of the propeller and the two thrusts acting on the adjuncts. Therefore, further studies are required to systematically conduct tests for each speed and operation angle of the azimuth propeller and to derive the optimal method for stopping ships by summarizing the results in a lookup table.

\section{Acknowledgements}

This study was funded by the National University Promotion Program for Pukyong National University in 2019.

\section{References}

Nowicki, J. (2014). Stopping of Ships Equipped with Azipods. International Journal on Marine Navigation and Safety of Sea Transportation, 8(3), 373-376. https://doi.org/10.12716/1001. 08.03.07

ITTC. (2017). Full Scale Manoeuvring Trials. ITTC Recommended Procedures and Guidelines, Revision 02, 7.5-04-02-01.

IMO. (2002). Standards for Ship Manoeuvrability. Ressolution MSC, 137(76), MSC 76/23/Add.1-Annex 6.

Sun, C., Wang, J., \& Wan, D. (2018). Numerical Simulations of Ship Stopping Maneuver With Reversing Propeller. In The Thirteenth ISOPE Pacific/Asia Offshore Mechanics Symposium, Jeju, Korea, ISOPE-P-18-005.

Ueno, M., Suzuki, R., \& Tsukada, Y. (2017). Estimation of Stopping Ability of Full-scale Ship using Free-running Model. Ocean Engineering, 130, 260-273. https://doi.org/10.1016/ j.oceaneng.2016.12.001

Yoshimura, Y. (1994). Studies on the stopping ability of a manoeuvring standard. Journal of the Society of Naval Architects of Japan, 176, 259-265.

Nakato, M., Kose, K., Terarnoto, S., \& Simamune, S. (1976). Experimental study on accelerating and decelerating ship motions. Journal of the Society of Naval Architects of Japan, $140,77-84$.

\section{Author ORCIDs and Contributions}
Author name
ORCID
Contributions
Park, Jong-Yong
0000-0002-5200-6012
(3)(4)(5)
Oh, Pilgun
0000-0001-8601-8380
(5)
Kim, Taejin
$0000-0001-8222-8647$
Lee, Jun-Ho
0000-0002-3747-167X
(5)
(1)(2)
(1) Conceived of the presented idea or developed the theory
(2) Carried out the experiment or collected the data
(3) Performed the analytic calculations or numerical simulations
(4) Wrote the manuscript
(5) Supervised the findings of this study 